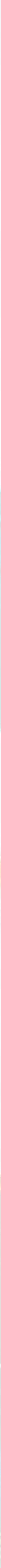




\title{
TALK AND PEDAGOGY: PARTICULARITIES OF A LANGUAGE CLASSROOM INTERACTION
}

\section{El habla y la pedagogía: particularidades en la interacción de una clase de idiomas}

\author{
Yohan Sneider Tiria Sotelo1, Erika Alexandra Prieto Wilches ${ }^{2}$ \\ 1-2Universidad Pedagógica y Tecnológica de Colombia, Sede Sogamoso \\ Email: ${ }^{1} y o h a n . t i r i a @ u p t c . e d u . c o,{ }^{2}$ erika.prieto@uptc.edu.co
}

(Recibido el 15 de mayo de 2021 - Aceptado el 26 de mayo de 2021)

\begin{abstract}
This paper aims at identifying some of the main features that a language classroom possesses regarding interaction. Conversation analysis was used to approach classroom talk and build reflection and understanding. For data to be gathered, a language lesson conducted in a public university with adult students was video recorded, divided in chunks and transcribed. Three extracts from the lesson were taken as a source of analysis and issues as identity, repair and turn taking presented on them were identified. Findings made evident the co-construction of interaction and how it can affect or modify the identities performed by participants. Besides, allowing students to do self-repair arise as relevant actions to carry on for promoting more meaningful and authentic interaction.
\end{abstract}

Key words: conversation analysis, identity, repair, turn taking, interaction.

\section{Resumen}

Este trabajo pretende identificar algunas de las características que un salón de idiomas posee con respecto a la interacción. El análisis de la conversación fue usado para aproximarse a la conversación y construir entendimiento. Para la recolección de datos, se grabó en video una clase de lengua extranjera en una universidad pública, se seccionó y luego fue transcrita. Tres extractos fueron tomados de la clase como fuente de análisis y aspectos como identidad, corrección y toma de turnos fueron identificados. Los hallazgos hicieron evidente la construcción conjunta de la interacción y cómo esta afecta o modifica las identidades desempeñadas por los participantes. Además, modificar la corrección y permitir a los estudiantes hacer su propia corrección surgen como acciones relevantes a llevar a cabo para promover la interacción auténtica y significativa.

Palabras clave: análisis de la conversación, identidad, reparación, toma de turno, Interacción. 


\section{INTRODUCTION}

Conversation plays an important role in the maintenance of classroom interaction. This aspect is best seen in language lessons, where speaking and the development of speaking abilities has fast become a relevant concern in language learning. By means of conversation, teachers can engage students in activities that foster language exchange and deepen their understandings and negotiations of meaning (Zwiers \& Crawford, 2011). In this sense, various processes of conversation that are performed inside a classroom display some characteristics as the talk goes on; some examples of this are the way speakers allocate turns to interact, error- repairing or the identities performed by participants. Such aspects can serve as a source of valuable information to describe and analyze the impact that spoken interplay have on communication, pedagogy, teaching and learning processes, among other inherent components of education.

This study describes an analysis of three main extracts taken from a language lesson that was video-recorded in a public university with adult students. The video was sectioned into pieces and then transcribed to facilitate analysis in detail by making use of conversation analysis. It was a method that helped uncover the joint construction of interaction and the display of identities as constituent of classroom talk.

\section{LITERATURE REVIEW}

Foreign language settings possess an infinite number of characteristics and particularities that offer the researcher many details and opportunities to be analyzed. It can be described as "an extraordinary micro-world where plenty of situations, experiences and linguistic interventions take place" (Fajardo, 2008, p. 10). This study used conversation analysis (Henceforth CA) to identify key issues in a classroom interaction. In addition, notions of repair, identity and turn-taking are also defined as follows.

\section{CONVERSATION ANALYSIS}

Properties and particularities of language and the way humans make sense of it are some of the main reasons why conversation analysis has gained popularity among scholars recently. This approach is focused on language as social action and a significant amount of research has been done on people's discourse, explicitly conversation. The social organization of the activities displayed through talk, interaction, turn by turn development and also the way in which the turns fit in a conversation are some of the topics surrounding conversation analysis (Wooffit, 2005). CA uses transcriptions to create its analysis. Then, talk is transcribed and the researcher relies on the emic perspective starting from the 
data collection process to move forward on specific issues that are seen from a fine level of detail. Considering the information above, there are some issues this study was focused on that are listed as follows.

\section{REPAIR}

Classroom conversation and interaction is a process that involves several aspects in order to occur. Participants, contributions, culture, and turn organization, among others influence and modify the development of the conversation as it goes on. One of those influencing factors is the error, and in fact, the error correction that is generally attributed to the teacher in the form of repair. "Conversational repair is viewed by SLA researchers as the sociopsychological engine that enables learners to get comprehended input" (Markee, 2000 as cited in Seedhouse, 2004, p. 141). Repair is very particular from language classroom settings; it is not an aspect that could be easily seen in other contexts of conversation. Occurring conversation in language classrooms displays some difficulties regarding word choice, lack of knowledge, fluency, and articulation, among others that sometimes need to be tackled in order for the conversation to progress.

Seedhouse (2004) offered an understanding of repair as the treatment that is done to the occurring problems in interaction and language use. In addition, repair has some variations according to the way in which it is done. Clarification requests and confirmation checks arise as two main forms of repair. The former is done through questioning, which is one of the strategies teachers use the most to create interaction and learning; and the latter is done with the intention of making sure that the teacher has understood in a correct way what the student has said (Fajardo, 2008).

\section{IDENTITY}

In classroom talk, the categories of teacher and student have been strongly identified and analyzed providing some institutional differences between them (Richards, 2006). Talk and interaction offer a view of the social context and the identities attributed to participants according to their contributions and organization of turns. Identity has been studied by several scholars (Cooley, 1902; Ball, 1972; Mead, 1934) who have correlated opinions on how complex the notion of identity is and the contributions that several areas of knowledge make to its construction. The identity of the teacher is also approached by Hargreaves (1996) who says that it is influenced by the events and personal experiences he faces in his professional role. It means that identity is an evolving process that somehow might be co-constructed and that is why it is an interesting item of analysis when using CA. 
Transcriptions of classroom talk might serve as a source to recognize the identities portrayed in it. Zimmerman (1988) proposed three aspects of identity that are useful in analysis; the first one is discourse identity, that is "integral to the moment-by-moment organization of the interaction" (p.90). The second ones he proposed are situated identities such as teacher and student, and finally transportable identities which are "identities that are usually visible, that is, assignable or claimable on the basis of physical and culturally based insignia which furnish the intersubjective basis for categorization" (Zimmerman, 1998, p. 91).

\section{TURN TAKING}

Turn taking organization has been one of the main characteristics of Conversation Analysis. It is the transitions that interactants follow in a turn-by-turn basis (Fajardo, 2013). The teacher is generally the one who initiates the talk, and he decides on the follow up of the talk by making use of pre-allocation of the turns. Besides, students also make up part of this right by self-nominating themselves to talk.

The concepts discussed above arise as useful components to get started with CA. They also offer the researcher some visible features to be identified and hence analyzed.

\section{METHODOLOGY}

This study used the transcriptions of the conversation talk occurring in a language lesson conducted with 9 students between the ages of 20-26 years old. They attended an English class in a Spanish monolingual setting at public university. The lesson was video recorded and after watching the video several times, it was sectioned into pieces. Data gathered from those specific sections where chunks were transcribed and analyzed by using the CA approach and also following the emic perspective of research. In addition, this study was guided by the following question: How does CA reveal the particularities of interaction in a language classroom?

\section{DATA ANALYSIS}

Three main extracts of the lesson were taken as main source to analyze de data. Those extracts were transcribed and analyzed to a high level of detail, and they are presented as follows.

\section{Extract 1: (turns 01-23)}

Teacher and students are playing a game and they are divided into two groups. Group A and group $B$, they are selecting some pieces from a game and according to the number they choose they are asked a question. 


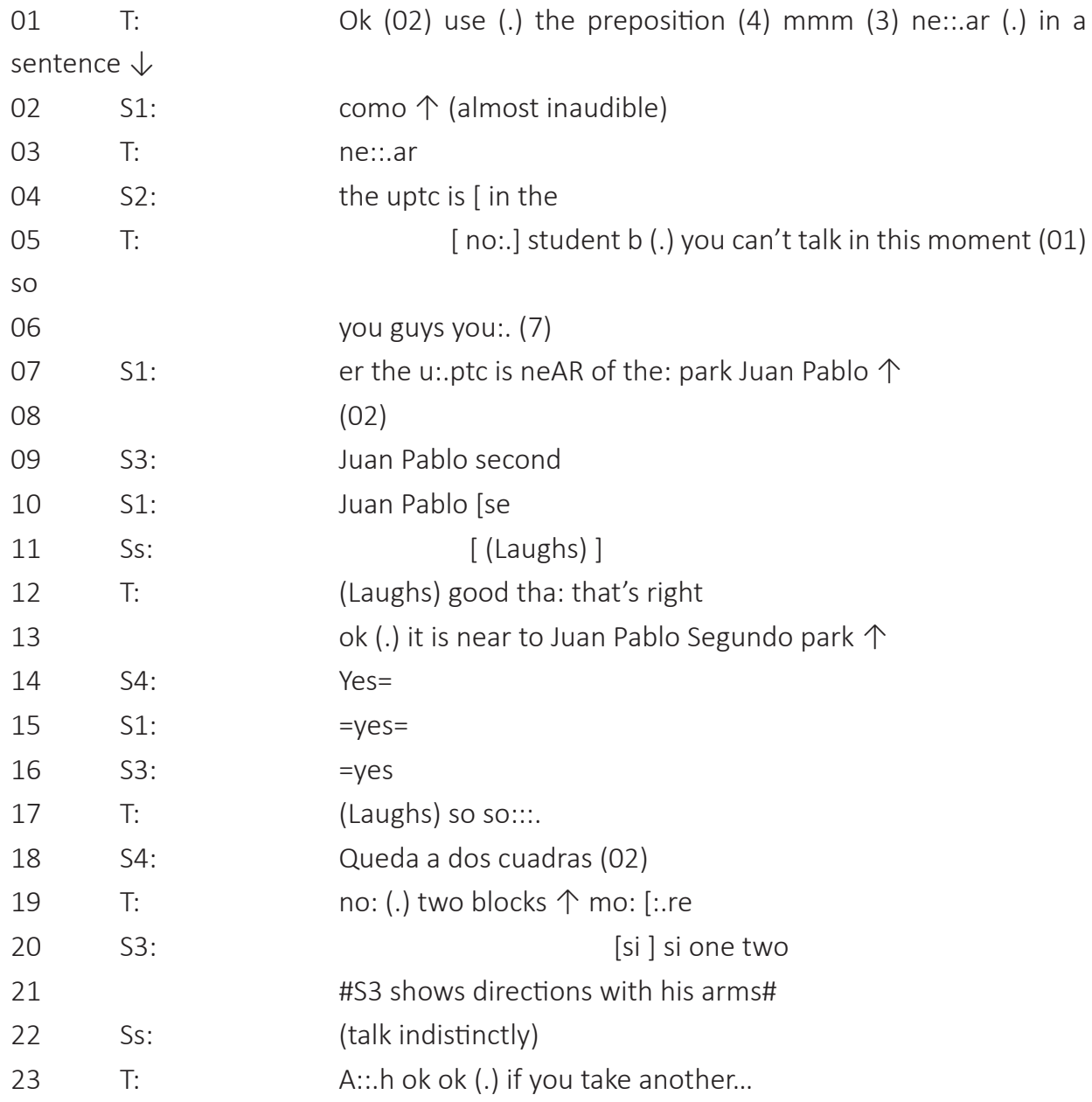

Extract 1 begins when the teacher is providing an exercise to the group A for them to make a sentence (turn 01) and uses the discourse maker ok which seems to be very particular of classrooms settings. Students belonging to group A are not able to listen clearly to the exercise and S1 self nominates to talk and uses the clarification request como (turn 02). The teacher clarifies the preposition they must use by making emphasis on it, and without making a direct pre-allocation of the turn we can see another self-nomination by S2 who starts building the sentence (turn 04). In his attempt to get involved in the activity that T had proposed previously, T overlaps S2 and does not allow her to continue with her contribution since she belongs to group $B$ and at the same time $T$ pre-allocates the turn (turns 05 \& 06). 
Responding to the pre-allocation of the turn addressed by the teacher, S1 makes a sentence, and starts the turn with a hesitant discourse marker er and ends with a 0.2 pause (turns $07 \&$ 08). The turn is preceded by the contribution of S3 who looks for a literal and funny way of translating a proper noun. In turn $12 \mathrm{~T}$ laughs as well, and it can be interpreted as a question of providing feedback. T shows affiliation to the students and in that way, $T$ encourages the learning process, because in this case the previous problem (turns 09 \& 10) is not repaired. Repair appears in turn 13 when T finally makes the right sentence in a form of self-initiated and self-repair.

This utterance of the teacher is preceded by the confirmation of the students by the latching presented in (turns 14 to 16) showing affiliation and changing the focus of the lesson from the linguistic part to a more content-oriented approach. All this is explained by the fact that interaction is promoted and increased from this point forward when the identity of the teacher moves from a very discourse and situated identity into a transportable one; in turn $17 \mathrm{~T}$ changes his role and accepts she does not know the right answer to the question already stated by hesitating so so: Which entails more participation from the students evidenced from turn 18 to 23.

The organization of the extract and the different contributions made by the students and the teacher display an interesting view of the identities performed by the participants. Since the very beginning of the turn constructional units, it is observable how default identities teacher and students are established (Richards, 2006). On one side, the teacher reflects a situated identity (turns $01,05,07 \& 19$ ), $T$ is there to teach, and specifically to teach language items and topics. The teacher also exercises power because he/she is the one who allocates turns, decides on the content, and somehow restricts the students' contributions (turn 05).

The role of the students remains passive until turn 13, but in this specific extract, it is evidenced how they play a very active role in the co-construction of the interaction when the participation is highly promoted, and $T$ is forced to move around communication rather than the items of language. This is also enhanced in turn 17 when $T$ hesitates about the content evidencing an asymmetry of knowledge that although it does not affect the situated identity of the teacher that much, it serves as a prompt for promoting more meaningful and authentic interaction. 


\section{Extract 2}

$\begin{array}{lll}01 & \text { T: } & \text { listen up (.) are there (02) Many universities in the city } \uparrow \\ 02 & & (02) \\ 03 & \text { S1: } & \text { in the city (01) are many universities } \downarrow \\ 04 & & (04) \\ 05 & & \text { (inaudible) Santo tomas, Uniboyaca, UPTC, UNAD. } \\ 06 & \text { T: } & \text { how many } \uparrow(02) \\ 07 & \text { S2: } & \text { cuantas } \uparrow \\ 08 & \text { S1: } & \text { five } \\ 09 & \text { T: } & \text { five so }(.) \text { there are a LOT or few } \uparrow \\ 10 & \text { S3: } & \text { a few } \\ 11 & \text { T: } & \text { few few yes }\end{array}$

Extract 2 begins with a discourse marker listen up to hold the floor and show the students that $T$ is there and needs the students' attention. This is followed by a very short pause and a question addressed to the students. Despite the pause that is presented in turn 02 , the teacher decides to wait and not to pre-allocate a turn. S1 self-nominates herself to complete the adjacency pair (turns 01 \& 03). The teacher's purpose is not accomplished in turn 03 when S1 tries to do a correct statement but there is a 0.1 pause and a not well-structured sentence due to the lack of grammar. The 0.4 pause displayed in turn 04 can be understood as an attempt of $T$ to allow the student to do self-repair, but it also fails. Instead, S1 looks for reasons to convince the teacher she is right through the exemplification of the universities located in the city. Turn 06 allows us to see that $T$ realizes that the question was not properly stated in turn 01 so she decides to reframe it in a simpler way and initiates a new Initiation-response- feedback/evaluation cycle (IRF/E). S2 identifies a 0.2 pause as a lack of understanding and translates cuantas (turn 07).

After that, the adjacency pair (turns 06 \& 08) is completed when S1 responds five. Turn 09 is the end of the IRF cycle with the feedback done by $T$ when repeating five, and T opens a new cycle in the same turn asking there are a lot of few being this question already pre-allocated to the same student. Finally, repair is seen in turns 10 and 11 in the form of other-initiated, other-repair, and turn 11 is at the same time the end of the cycle started in turn 09.

Relevant insights of the way that the teacher controls and manipulates students' contributions and interaction itself are revealed in this extract (turns 01, 06 \& 09). Although, turn 03 presents a problematic utterance that should be repaired, T remains silent and lets it pass because $T$ knows that one of the roles of being a teacher is mitigating the negative effects that correction might bring and creating a comfortable learning 
atmosphere. That is one reason why the repair in turn 11 is done through emphasizing the word instead of correcting the problem directly. Another aspect that is displayed in extracts 1 and 2 is how the students move ahead of the linguistic focus of the class into the production of more meaningful and authentic communication (turn 05). This is evidenced by the fact that they feel more engaged when they must talk about their context.

\section{Extract 3}

\begin{tabular}{|c|c|c|}
\hline 01 & $\mathrm{~T}:$ & ok (.) is the basilica in front OF Julio Flores park $\uparrow=$ \\
\hline 02 & S1: & $=$ No no the basilica (02) [ do \\
\hline 03 & S2: & [basilica in front ] \\
\hline 04 & S1: & do:es does (.) don't no doesn't er:.: \\
\hline 05 & $\mathrm{~T}:$ & the basilica:. $\uparrow$ \\
\hline 06 & S1: & doesn't = \\
\hline 07 & S3: & $=$ doesn't in front of the: $[:$. \\
\hline 08 & S1 & [doesn't is] doesn't is $\uparrow$ \\
\hline 09 & & $(02)$ \\
\hline 10 & S4: & No because doesn't (inaudible) \\
\hline 11 & $\mathrm{~T}:$ & \#Talking to another student\# \\
\hline 12 & & you can help her \\
\hline
\end{tabular}

Extract 3 begins with the discourse marker ok attributed to the teacher to hold the floor and call the students' attention (turn 01). After a short pause, the teacher asks a question that is addressed to all the students and immediately there is a latching and S1 completes the adjacency pair (turns $01 \& 02$ ) with a negative reply. This is followed by a 0.2-second pause that represents a lack of vocabulary and grammar knowledge, a reason why S3 overlaps and tries to respond but the goal is not accomplished either (turn 03). S1 again tries to find the right way of negating a sentence and until this point we can see a type of self-initiated repair but there is not repair yet (turn 04).

In turn 05, T prompts the students to continue but decides not to provide the right answer and allocates some time for students to continue co-constructing the interaction and building student-student repair. From turns 06 to 08 there is a clear view of how engaged the students are in the talk, as there are some latching and overlapping. After a 0.2 second pause in turn 09, S4 self-nominates to contribute to solve the problem and finally $T$ pre-allocates the turn to one student to help as well, enhancing in that way the student-student repair.

Although, the perception of repair is addressed to error correction and the teacher as the one who corrects; this extract presents a variation of repair influenced by the pedagogical 
focus (Van Lier, 1988). In extract 3 the teacher is not the one who makes the repair, instead, T leaves a long time of the talk for students to have the power and freedom to do self-repair. The role of the teacher is changed here, and this chance given to the students is reflected in the number of contributions they make which is bigger than the teachers.

\section{CONCLUSIONS}

Data analysis and the study per se, displayed relevant insights of how participants in the interaction inside a classroom perform identities that are affected by the coconstruction of such interplay as the conversation goes on. The teacher is generally placed over students; he/she is the one who decides on the content, the organization of the talk and the teacher even has the power to restrict the students' contributions. However, it was seen that students can also exercise the right to construct interaction by themselves, changing the teacher's agenda and even the pedagogical focus to build more authentic language, communication, and learning. This shift in identities and structure of conversation is what teachers should take advantage of to take lessons to deeper levels of thinking (Zwiers \& Crawford, 2011). It arises as an opportunity to go beyond checking limited language items or only specific content, to deepen thoughts reflected in students' contributions and conversation itself.

Considering, communication (verbal and non-verbal) plays an important role. It was noticed that students use different means to make themselves understood, that is the reason why teachers should focus not only on language items, but also on these kinds of resources that let interaction happen.

In addition, the extracts presented an interesting view of one of the teacher's roles inside the classroom: adapting correction into ways that mitigate its negative effects as a form to promote an accurate and relaxed environment for learning to occur. It is a resource that reduces shyness or fear to participate and at the same time empowers students to talk. Moreover, this strategy of letting students be the owner of their corrections arises as a pivotal factor to modify the IRF/E (initiation-response-feedback/evaluation) cycle; which tends to be the mainstream in conversation. This type of cycle reduces the number of interactions presented by participants because in some cases the teacher is the one who initiates (initiation) and closes (feedback/evaluation) the interplay. As it was seen in the data, when the teacher does not correct immediately, he/she is creating a space of self-regulation in which students talk among themselves to get their own feedback. More meaningful interaction is one of the advantages of adapting correction, and studentstudent repair arises as a particularity of language classrooms that should be promoted. 


\section{REFERENCES}

Fajardo, J. (2008). Conversation analysis (CA): Portraits of interaction in a foreign language classroom. Enletawa journal, (1), 9-22.

Fajardo, J. (2013). What makes a teacher: identity and classroom talk. Cuadernos de linguistica hispánica., (22), 127-146.

Richards, K. (2008). Being the teacher: identity and classroom conversation. Applied linguistics, 27 (1), 51-77.

Seedhouse, P. (2004). The interactional architecture of the language classroom: a conversation analysis perspective. London: Blackwell.

Van Lier, L. (1988). The classroom and the language learner. New York: Longman.

Wooffitt, R. (2005). Conversation Analysis and Discourse Analysis: A Comparative and Critical Introduction. SAGE Publications Ltd.

Zimmerman, D. (1998). Discoursal identities and social identities. In C. Antaki and S. Widdicombe (eds.): identities in talk. London: sage, pp. 87-106.

Zwiers, J., Crawford, M. (2011). Academic conversations: classroom talk that fosters critical thinking and content understandings. Portland: Stenhouse publishers. 